THU0538 ABSTRACT WITHDRAWN

\section{THU0539 SERUM SOLUBLE CD25: AN USEFUL BIOMARKER OF MACROPHAGE ACTIVATION SYNDROME IN SYSTEMIC JUVENILE IDIOPATHIC ARTHRITIS}

Sandesh Guleria ${ }^{1}$, Anju Gupta ${ }^{1}$, Amit Rawat ${ }^{1}$, Prateek Bhatia ${ }^{2} .{ }^{1}$ Post Graduate Institute of Medical Education and Research, Chandigarh, Allergy Immunology unit, department of Pediatrics, Chandigarh, India; ${ }^{2}$ Post Graduate Institute of Medical Education and Research, Chandigarh, Pediatric hemato-oncology unit, department of pediatrics, Chandigarh, India

Background: Systemic juvenile idiopathic arthritis (SJIA) is an auto-inflammatory disorder secondary to innate immune dysfunction with a propensity to develop macrophage activation syndrome (MAS), a life-threatening condition (1). sCD25 has been used as a sensitive biomarker for the diagnosis of Hemophagocytic lymphohistiocytosis which has similarities in clinical features and pathogenesis to MAS (2).

Objectives: To assay serum soluble CD25 in children with systemic juvenile idiopathic arthritis (SJIA) and to compare levels of SCD25 in children with inactive disease, active disease and those with macrophage activation syndrome (MAS).

Methods: This prospective study was conducted in a tertiary care referral centre in North India from January 2017 to June 2018. All patients fulfilling the International League of Associations for Rheumatology (ILAR) 2001 criteria for SJIA were eligible for enrolment. At enrolment, all patients were examined clinically for signs of disease activity. Appropriate investigations were carried out and SCD25 was analyzed by using commercially available sCD25/IL-2R ELISA kit.

Results: A total of 35 children (1-18 years) with 43 events were included in the study. Mean age at enrolment in the study was $7.3 \pm 3.59$ years with male to female ratio of 2.5. Based on clinical features and investigations, events were categorized into 3 groups; SJIA with inactive disease $(15 ; 34.9 \%)$, SJIA with active disease $(15 ; 34.9 \%)$ and SJIA with MAS (13; 30.2\%). Mean sCD25 levels in the study population were 10,966.02 $\pm 10,854.93 \mathrm{pg} / \mathrm{ml}$. Children with inactive disease, active disease and disease with MAS had mean \pm SD serum sCD25 levels of $4710.6 \pm$ $1817.04 \mathrm{pg} / \mathrm{ml}, 7604 \pm 2376.24 \mathrm{pg} / \mathrm{ml}$, and $22062.9 \pm 14335.97 \mathrm{pg} / \mathrm{ml}$ respectively. Although, Mean level of $\mathrm{sCD} 25$ in children with active disease was higher than those with inactive disease, but no significant difference could be found. sCD25 levels significantly ( $p$ value 0.0001 ) varied between MAS and other 2 groups. SCD25 cut off level of 10,385 $\mathrm{pg} / \mathrm{ml}$ was found to have sensitivity of $100 \%$ and specificity of $96.7 \%$ in differentiating MAS in SJIA from disease flare and inactive disease. There was no significant correlation of SCD25 with demographic parameters, Total leucocyte count, erythrocyte sedimentation rate (ESR), C-reactive protein (CRP), platelet counts, urea, creatinine, prothrombin time, activated partial prothrombin time and fibrinogen levels. A correlation of sCD25 was found with levels of haemoglobin ( $p$-value .01), ferritin ( $p$-value .001), aspartate aminotransferase (AST) ( $p$-value .000), alanine aminotransferase (ALT) ( $p$-value .000), alkaline phosphatase (ALP) ( $p$-value .005) and triglycerides ( $p$-value .001). Higher sCD25 levels were found in patients who had low $\mathrm{Hb}$, elevated ferritin, elevated AST, ALT, ALP and serum triglyceride levels.

Conclusion: sCD25 is a useful biomarker in differentiating MAS in SJIA from disease flare and inactive disease with sensitivity and specificity of $100 \%$ and $96.7 \%$ respectively at a cut off level of $10,385 \mathrm{pg} / \mathrm{ml}$. Coupling sCD25 with other laboratory parameters may be useful for early diagnosis of MAS in SJIA.

\section{REFERENCES:}

[1] Kelly A, Ramanan AV. Recognition and management of macrophage activation syndrome in juvenile arthritis. Curr Opin Rheumatol. 2007;19:47781.

[2] Henter J-I, Horne A, Aricó M, Egeler RM, Filipovich AH, Imashuku S, et al. HLH-2004: Diagnostic and therapeutic guidelines for hemophagocytic lymphohistiocytosis. Pediatr Blood Cancer. 2007;48:124-31.

Disclosure of Interests: None declared

DOI: 10.1136/annrheumdis-2019-eular.3038

\section{THU0540 \\ SYSTEMATIC REVIEW OF BIOLOGICAL TREATMENT OF DEFICIENCY OF INTERLEUKIN-36 RECEPTOR ANTAGONIST (DITRA) IN CHILDREN AND ADOLESCENTS}

Toni Hospach ${ }^{1}$, Fabian Glowatzki ${ }^{1}$, Friederike Blankenburg ${ }^{1}$,

Dennis Conzelmann ${ }^{1}$, Christian Strinkorb ${ }^{1}$, Chris Sandra Muellerschoen ${ }^{2}$, Peter Driesch von den ${ }^{2}$, Lisa Koehler ${ }^{3}$, Meino Rohlfs ${ }^{3}$, Christoph Klein ${ }^{3}$, Fabian Hauck ${ }^{3}$. ${ }^{1}$ Klinikum Stuttgart Olgahospital, Pediatric Rheumatology, Stuttgart, Germany;

${ }^{2}$ Klinikum Stuttgart Bad Cannstatt, Stuttgart, Germany; ${ }^{3}$ Dr. von Hauner Children's Hospital, University Hospital, LMU, Munich, Germany

Background: Deficiency of interleukin-36 receptor antagonist (DITRA) is a life threatening autoinflammatory disease caused by autosomal recessive mutations of the IL36RN gene leading to recurrent episodes of generalized pustular psoriasis with systemic inflammation and fever. The disease is rare and no standardized treatment guidelines exist

Objectives: To systematically review and analyze the literature on biologically treated pediatric DITRA patients

Methods: A NCBI pubmed database research was performed to identify all relevant articles on pediatric DITRA patients treated with biologicals According to defined response criteria therapeutic efficacy was analyzed.

Results: Our literature research revealed 13 pediatric patients with DITRA and biolocial treatment. Ten patients were homozygous including six with the p.Leu27Pro, three with the p.Arg10 Argfs* and one with the $p$ Thr123Met mutation and three were compound heterozygous. We add an unreported DITRA patient with a compound heterozygous IL36RN p. Pro76Leu/pSer113Leu mutation. In total 29 flares in 14 patients were treated with biological agents- targeting IL-1/R, IL-17, IL-12/23 and TNF- $\alpha$. Complete response was achieved in $15(52 \%)$, partial in $4(14 \%)$, and no response in $10(34 \%)$ of the flares. Response rates were heterogeneous among the different agents. While complete/partial/no response with inhibition of TNF-alpha could be achieved in $6(46 \%) / 3(23 \%) / 4(31 \%)$, the inhibition of IL-17 and of IL-12/23 led in each 4 flares to a $100 \%$ complete response. IL-1/R inhibition led to complete/partial response in each $1(13 \%)$ and was not effective in $6(75 \%)$ flares. Of note, the unreported patient was successfully treated with weekly dosed adalimumab.

Conclusion: DITRA is a rare disease that has to be considered in patients with generalized pustular psoriasis with systemic inflammation and fever. It can be effectively treated with specific biological inhibition of TNF-alpha, IL-12/23 and IL- 17, while anti-IL-1/R treatment seems less effective. Weekly dosed adalimumab appears to be a novel treatment option for pediatric patients. Further reports and studies of biological treated pediatric DITRA patients are warranted for evaluation of optimal treatment.

\section{REFERENCE:}

[1] Marrakchi, S., P. Guigue, et al. (2011). "Interleukin-36-receptor antagonist deficiency and generalized pustular psoriasis." N Engl J Med 365(7): 620628.

Disclosure of Interests: Toni Hospach Speakers bureau: Chugai, Roche, Novartis, Fabian Glowatzki: None declared, Friederike Blankenburg: None declared, Dennis Conzelmann: None declared, Christian Strinkorb: None declared, Chris Sandra Muellerschoen: None declared, Peter Driesch von den: None declared, Lisa Koehler: None declared, Meino Rohlfs: None declared, Christoph Klein: None declared, Fabian Hauck: None declared DOI: 10.1136/annrheumdis-2019-eular.1184

\section{THU0541 ANTI-VACCINE ANTIBODY LEVELS IN JUVENILE IDIOPATHIC ARTHRITIS PATIENTS: PRELIMINARY} DATA IN 90 PATIENTS

Natalia Lubimova ${ }^{1}$, Olga Goleva ${ }^{2}$, Irina Fridman ${ }^{2}$, Lubov Sorokina ${ }^{3}$,

Rena Idrisova ${ }^{4}$, Susanna Kharit ${ }^{2}, 3$, Mikhail Kostik ${ }^{3} .{ }^{1}$ Children's City Hospital \# 2 na Saint Mary Magdalene, Saint-Petersburg, Russian Federation; ${ }^{2}$ Pediatric Research and Clinical Center for Infection Diseases, Saint-Petersburg, Russian Federation; ${ }^{3}$ Saint-Petersburg State Pediatric Medical University, Saint-Petersburg, Russian Federation; ${ }^{4}$ Children's City Hospital\#1, Saint-Petersburg, Russian Federation

Background: Patients with juvenile idiopathic arthritis (JIA) may have lower protective levels of anti-vaccine antibodies (AVA) due to high inflammatory activity, interrupted or incomplete vaccination schedule, using of immune-modulating drugs, e.g. systemic corticosteroids (CS), methotrexate (MTX) and biologics [1]

Objectives: The aim of our study was to evaluate levels of AVA in the patients with JIA. 
Methods: We included data about 90 JIA (26 M and 64 F) aged from 2 to 17 years, who received scheduled vaccination before the age of 2 years and before JIA onset. In all patients the $\lg G$ anti-measles (AM), anti-parotitis (AP), anti-hepatitis $B(A H B)$, anti-diphtheria $(A D)$ and antirubella (AR) AVA levels were detected with ELISA. In each patient we evaluate the type of the JIA (oligoarthritis - OA $(n=38)$, polyarthritis - PA $(n=36)$, systemic-SA $(n=7)$ and enthesitis-related arthritis - ERA $(n=10)$, routine disease activity and treatment. In healthy controls were measured anti-measles $(n=40)$ and anti-parotitis $(n=30)$ antibodies (AB) for comparison with JIA.

Results: The main demographic characteristics: age of inclusion in the study 11 (8-15) years, disease onset-6 (4-8) years, JIA duration-4 (2-7) years. The $A M A B$ in JIA patients were $0.2(0.0-0.5) \mathrm{IU} / \mathrm{ml}$ and in $\mathrm{HC}$ $0.3(0.2-1.1) \mathrm{IU} / \mathrm{ml} \quad(p=0.00002)$, despite the higher age of JIA patients than $\mathrm{HC}(\mathrm{p}=0.0000001)$; $\mathrm{AP} A B$ were $2.6(1.0-5.1) \mathrm{IU} / \mathrm{ml}$ vs $1.1(0.0-4.9)$ $\mathrm{IU} / \mathrm{ml}$ in $\mathrm{JIA}$ and $\mathrm{HC}$, respectively $(p=0.08)$. Protective levels of $A M A B$ was detected in $50 \%$ of all JIA population, vs. $\mathrm{HC}-87.5 \% \quad(p=0.00005)$, AP-67.7\% vs. $60 \%$ in $\mathrm{HC} \quad(p=0.076), \mathrm{AHB}-54.4 \%, \mathrm{AD}-50 \%$, AR$97.8 \%$. The main data related to vaccination status in the table. We have found correlation between JIA duration and levels AM AB ( $r=-0.27$, $p=0.015), \quad A P$ AB $(r=-0.22, p=0.039), \quad A D \quad A B(r=-0.27, p=0.015) ; \quad M T X$ treatment with $A M A B(r=-0.37, p=0.001)$, and $A D A B(r=-0.29, p=0.007)$; treatment with biologics and $A M A B(r=-0.25, p=0.018)$, and using more than one biologics with $A R A B(r=-0.27, p=0.047)$. In the regression model only MTX had a negative impact on $A M(r=-0.001)$ and $A D A B$ level $(p=0.01)$.

\begin{tabular}{lccccc}
\hline Parameter & OA & PA & SA & ERA & P \\
\hline Onset age, y & $5(4-7)$ & $6(4-8)$ & $8(4-11)$ & $9(7-12)$ & 0.01 \\
JIA duration, y & $3(2-5)$ & $5.4(2-9)$ & $4(1-6)$ & $6(5-10)$ & 0.006 \\
\# AM vaccinations & $2(1-2)$ & $2(1-2)$ & $1(1-2)$ & $2(2-2)$ & 0.005 \\
\# of patients with AM & 51 & 60 & 43 & 100 & 0.06 \\
revaccination,\% & & & & & \\
AM IgG, IU/ml & $0.2(0-0.6)$ & $0(0-0.4)$ & $0.2(0 ; 1.6)$ & $0.2(0.1-$ & 0.2 \\
& & & & $0.3)$ & \\
Protective AM IgG level,\% & 58 & 39 & 57 & 50 & 0.42 \\
\# of patients with AP & 50 & 61 & 43 & 100 & 0.05 \\
revaccination,\% & & & & & \\
\# AP vaccinations & $1.5(1-2)$ & $2(1-2)$ & $1(1-2)$ & $2(2-2)$ & 0.004 \\
AP IgG, IU/ml & $3(1.5-5)$ & $2.3(0-5)$ & $1.3(0 ; 5)$ & $2.6(1.1-$ & 0.67 \\
& & & & $3.3)$ & \\
Protective AP IgG level,\% & 82 & 72 & 71 & 75 & 0.8 \\
\# AD vaccinations & $4(4-5)$ & $5(4-5)$ & $4(4-5)$ & $5(4-6)$ & 0.09 \\
AD IgG, IU/ml & $0.1(0.03-$ & $0.1(0.03-$ & $0.04(0.0 ;$ & $0.16(0.05-$ & 0.64 \\
& $0.3)$ & $0.2)$ & $0.2)$ & $0.4)$ & \\
Protective AD IgG level,\% & 53 & 50 & 29 & 50 & 0.71 \\
\# AHB vaccinations & $3(3-3)$ & $3(3-3)$ & $3(3-3)$ & $3(3-3)$ & 0.87 \\
AHB IgG, IU/ml & $5(0-20)$ & $17(2-45)$ & $1(0 ; 10)$ & $19(4-228)$ & 0.09 \\
Protective AHB IgG level,\% & 45 & 67 & $29)$ & 63 & 0.13 \\
\# AR vaccinations & $1(1-2)$ & $1(1-2)$ & $1(1-1)$ & $2(2-2)$ & 0.57 \\
AR IgG, IU/ml & $72(35-$ & $54(27-96)$ & $200(18 ;$ & $67(42-$ & 0.52 \\
& $145)$ & \multicolumn{5}{c}{$200)$} & $2000)$ & \\
Protective AR IgG level,\% & 100 & 97 & 100 & 100 & 0.69 \\
\hline
\end{tabular}

Conclusion: Children with JIA are in the risk of decreased level of AVA, especially in measles, diphtheria and parotitis. The measurements of AVA in the individual JIA vaccination schedule required.

\section{REFERENCES:}

[1] Toplak N, Avčin T. Long-term safety and efficacy of varicella vaccination in children with juvenile idiopathic arthritis treated with biologic therapy. Vaccine. 2015; 33(33):4056-9.

Disclosure of Interests: None declared

DOI: 10.1136/annrheumdis-2019-eular.2721

\section{THU0542 THE PSYCHIATRIC DISORDERS IN CHILDHOOD, ADOLESCENCE AND YOUNG ADULTS WITH JUVENILE IDIOPATHIC ARTHRITIS PATIENTS IN FINLAND}

Minna Kyllönen ${ }^{1}$, Hannu Kautiainen ${ }^{2}$, Kari Puolakka ${ }^{3}$, Paula Vähäsalo ${ }^{4}$. ${ }^{1}$ Department of Internal Medicine, Oulu University Hospital, Oulu, Finland; ${ }^{2}$ Department of Medicine and Primary Health Care, University of Helsinki, Helsinki, Finland; ${ }^{3}$ South Karelia Central Hospital, Lappeenranta, Finland; ${ }^{4}$ Department of Pediatrics, Oulu University Hospital, Oulu, Finland

Background: Reported psychiatric morbidity among juvenile idiopathic arthritis (JIA) patients has varied between $9.3-51 \%$ (1-3). The variation between studies can be explained by differences in the study populations (age, disease duration and disease state) and differences in the study methods (1-3). Depression and anxiety are the most common disorders, but most studies were based on questionnaires to investigate incidence of only these two diseases $(1,3)$

Objectives: To explore mental and behavioral disorders in JIA patients compared to the control population.

Methods: All incidents patients with JIA during 2000-2014 were collected from the nationwide register, maintained by the Social Insurance Institution of Finland (4). The National Population Registry identified three controls (similar regarding age, sex and residence) for each case. They were followed up together until $31^{\text {st }}$ Dec 2015 . ICD-10 codes of psychiatric diagnosis (F10-F99) were picked up from the Care Register for Health Care of the National Institute for Health and Welfare

Results: During 28,941 follow-up years, 974 (23\%) JIA patients were diagnosed with mental or behavioral disorders, whereas the number in the control group was $1,807 \quad(15 \%), \quad(p<0.001)$. Neurotic, stress-related and somatoform disorders (F40-48) and mood (affective) disorders (F3039) were the most common psychiatric diagnoses in the JIA $(10.41 \%$ and $8.18 \%)$ and in the control group $(5.44 \%$ and $5.13 \%)$. The odds ratio for neurotic disorders (F40-48) was $2.02(95 \% \mathrm{Cl} 1.78-2.29)$ and for mood disorders (F30-39) $1.65(95 \% \mathrm{Cl}$ 1.44-1.89). Additionally, JIA was statistically significantly associated with behavioral and emotional disorders and disorders of psychological development (Table). Female patients with JIA had higher odds ratios than males for all mental and behavioral disorders except behavioral syndromes (F50-59), for which males with JIA had higher odds ratio.

Conclusion: The risk of psychiatric disorders in JIA patients is increased.

\section{REFERENCES}

[1] Raab A, Sengler C, Niewerth M, Klotsche J, Horneff G, Zink A, et al. Comorbidity profiles among adult patients with juvenile idiopathic arthritis results of a biologic register. Clin Exp Rheumatol 2013;31(5): 796-802.

[2] Vandvik I. Mental Health and psychosocial functioning in children with recent onset of rheumatic disease. J. Child Psychol. Psychiat. 1990; 3:961-971.

[3] Packham JC, Hall MA \& Pimm TJ. Long-term follow-up of 246 adults with juvenile idiopathic arthritis: predictive factors for mood and pain. Rheumatology (Oxford) 2002;41(12): 1444-1449.

[4] Kyllönen MS, Kautiainen H, Puolakka K, Vähäsalo P. The mortality rate and causes of death among juvenile idiopathic arthritis patients in Finland Clin exp Rheumatol. 2019; in press.

Abstract THU0542 -Table 1. Percentages and odds ratios (OR) for psychiatric disorders in JIA compared to controls

\begin{tabular}{lccc}
\hline Psychiatric disorders (ICD-10) & $\begin{array}{c}\text { JIA n/ } \\
\%\end{array}$ & $\begin{array}{c}\text { Controls } \\
\mathrm{n} / \%\end{array}$ & OR (95\% Cl) \\
\hline Mental and behavioral disorders due to psychoactive & $70 /$ & $212 / 1.69$ & $0.99(95 \% \mathrm{Cl}$ \\
substance use & 1.67 & & $0.75-1.30)$ \\
(F10-19) & & & \\
Schizophrenia, schizotypal and delusional disorders & $31 /$ & $68 / 0.54$ & $1.37(95 \% \mathrm{Cl}$ \\
(F20-29) & 0.74 & & $0.89-2.09)$ \\
Mood (affective) disorders & $342 /$ & $642 / 5.13$ & $\mathbf{1 . 6 5}(\mathbf{9 5} \% \mathbf{C l}$ \\
(F30-39) & 8.18 & & $\mathbf{1 . 4 4 - 1 . 8 9 )}$ \\
Neurotic, stress-related and somatoform disorders & $435 /$ & $681 / 5.44$ & $\mathbf{2 . 0 2}(\mathbf{9 5} \% \mathbf{C l}$ \\
(F40-49) & 10.41 & & $\mathbf{1 . 7 8 - 2 . 2 9 )}$ \\
Behavioral syndromes & $134 /$ & $204 / 1.63$ & $\mathbf{2 . 0 0}(\mathbf{9 5} \% \mathbf{C l}$ \\
(F50-59) & 3.21 & & $\mathbf{1 . 6 0 - 2 . 4 9 )}$ \\
Disorders of adult personality and behavior & $34 /$ & $80 / 0.64$ & $1.27(95 \% \mathrm{Cl}$ \\
(F60-69) & 0.81 & & $0.85-1.91)$ \\
Disorders of psychological development & $192 /$ & $414 / 3.31$ & $\mathbf{1 . 4 1}(\mathbf{9 5} \% \mathbf{C l}$ \\
(F80-89) & 4.59 & & $\mathbf{1 . 1 8 - 1 . 6 8 )}$ \\
Behavioral and emotional disorders and unspecified & $192 /$ & $414 / 3.31$ & $\mathbf{1 . 4 1}(\mathbf{9 5} \% \mathbf{C l}$ \\
mental disorder (F90-99) & 4.59 & & $\mathbf{1 . 1 8 - 1 . 6 8 )}$ \\
\hline & & &
\end{tabular}

Disclosure of Interests: None declared

DOI: 10.1136/annrheumdis-2019-eular.1941

\section{THU0543 LATENT TUBERCULOSIS INFECTION IN CHILDREN WITH PEDIATRIC RHEUMATOLOGIC DISEASES TREATED WITH CANAKINUMAB}

Balahan Makay ${ }^{1}$, Ozge Altug Gucenmez ${ }^{1}$, Illknur Çağlar ${ }^{2}$, Süleyman Nuri Bayram², Nesrin Gülez ${ }^{1}$, Illker Devrim ${ }^{2} .{ }^{1}$ Dr. Behçet Uz Children's Hospital, Department of Pediatric Rheumatology, Izmir, Turkey, ${ }^{2}$ Dr. Behçet Uz Children's Hospital, Department of Pediatric Infectious Diseases, izmir, Turkey

Background: Little is known about the long-term safety of canakinumab about tuberculosis (TB) risk in paediatric rheumatologic diseases. 